\title{
De Sanctis-Cacchione Syndrome
}

National Cancer Institute

\section{Source}

National Cancer Institute. De Sanctis-Cacchione Syndrome. NCI Thesaurus. Code C84666.

A rare autosomal recessive inherited syndrome. It is characterized by xeroderma pigmentosum, mental retardation, dwarfism, hypogonadism, and neurologic abnormalities. 